Dziemianko, Anna. 'On the use(fulness) of paper and electronic dictionaries.' In Granger, Sylviane and Magali Paquot (eds.), Electronic Lexicography. Oxford: Oxford University Press. Pre-publication draft. Not for quotation or copying.

\title{
On the use(fulness) of paper and electronic dictionaries
}

\author{
Anna Dziemianko
}

\section{Introduction}

The distinction between paper and electronic dictionaries represents an aspect of the presentational, or tectonic, typology of dictionaries which focuses on the medium (Hartmann and James 1998: vi). Human-oriented electronic dictionaries (possibly with some NLP extensions), considered below, are "collections of structured electronic data that can be accessed with multiple tools, enhanced with a wide range of functionalities, and used in various environments" (De Schryver 2003: 146). Different types of electronic dictionaries can be distinguished. De Schryver (2003) reviews the classifications of electronic dictionaries developed by Martin (1992), Lehr (1996), and Nesi (2000a), but considers them inadequate to account for the increasing variety of electronic dictionaries and puts forward his own threestep typology, centred around the question "who accesses what, where?".

The answer to the first part of the question, i.e. "who accesses the dictionary?" is machines or humans. The second aspect, i.e. "what is accessed?" boils down to the dictionary medium, which can be non-electronic (physical) or electronic. Each medium involves handheld devices and robust machines. Finally, the question "where does one access the dictionary data?" is related to the type of storage. Considering the physical medium, the printed page, for example, is a handheld device, while the microfiche, read with the help of non-portable equipment, is a robust machine device. With respect to the electronic medium, de Schryver (2003) draws a distinction between electronic dictionaries on stand-alone computers (e.g. handheld dictionaries, such as pocket electronic dictionaries (PEDs) or reading pens, and robust-machine dictionaries typically stored in CDs, DVDs or hard disks) and those on networked computers (intranet and internet dictionaries).

Although De Schryver (2003: 147) held that his typology was flexible enough to account for future innovations, the classification, proposed almost a decade ago, has already been extended, supplemented and refined. Fuertes-Oliviera (2009) recognises two types of internet dictionaries: institutional internet reference works and collective multiple-language internet reference works, depending on who compiles such dictionaries for whom and whether they are available for free or not. Institutional internet reference works are dictionaries created by an identifiable institution and may be free to use or not. Collective multiple-language reference works, such as Wiktionary, are usually free and result from collaborative effort taken by a community of users. In a recent review of online dictionaries of English, Lew (2011) also discusses portals with hyperlinks to dictionaries (e.g. WordReference.com or Cambridge Dictionaries Online) and dictionary aggregators (e.g. 
Dziemianko, Anna. 'On the use(fulness) of paper and electronic dictionaries.' In Granger, Sylviane and Magali Paquot (eds.), Electronic Lexicography. Oxford: Oxford University Press. Pre-publication draft. Not for quotation or copying.

TheFreeDictionary and Dictionary.com), where information drawn from several dictionaries is pasted on one website.

The potentiall of electronic dictionaries is widely recognised (e.g. Bergenholtz and Gouws 2007, de Schryver 2003, Harley 2000, Lew 2011, Nesi 1999, Prinsloo 2005). De Schryver (2003: 163-187) alone mentions as many as 118 advantages of electronic dictionaries over paper dictionaries. The increasing popularity of electronic dictionaries can be put down to better readability of entries and improved retrieval systems, including hypertext, wildcards, pronunciation-based and full text searches (Nesi 2000a: 839; Tono 2009: 40; Lew, this volume). Electronic dictionaries typically store much more than the entire content of thick paper dictionaries, offer direct access to corpus examples and citation banks and open a number of new search routes, such as tracking down a target word via phonologically similar or lexically related words (Nesi 1999: 59). Tools for textual condensation (Wiegand 1996) such as swung dashes, slashes, grammar codes and abbreviations are less necessary, since in the electronic format space constraints are much less of an issue (except for relatively new media, such as PEDs, where not so much disc space as screen space still needs to be reckoned with). Thus, full syntactic descriptions have replaced grammar codes, and hyperlinks ensure quick access to further relevant information (Harley: 2000). The following screenshot from e-CALD3 illustrates how the user can easily access information on semantic relations (here: synonyms of murder).

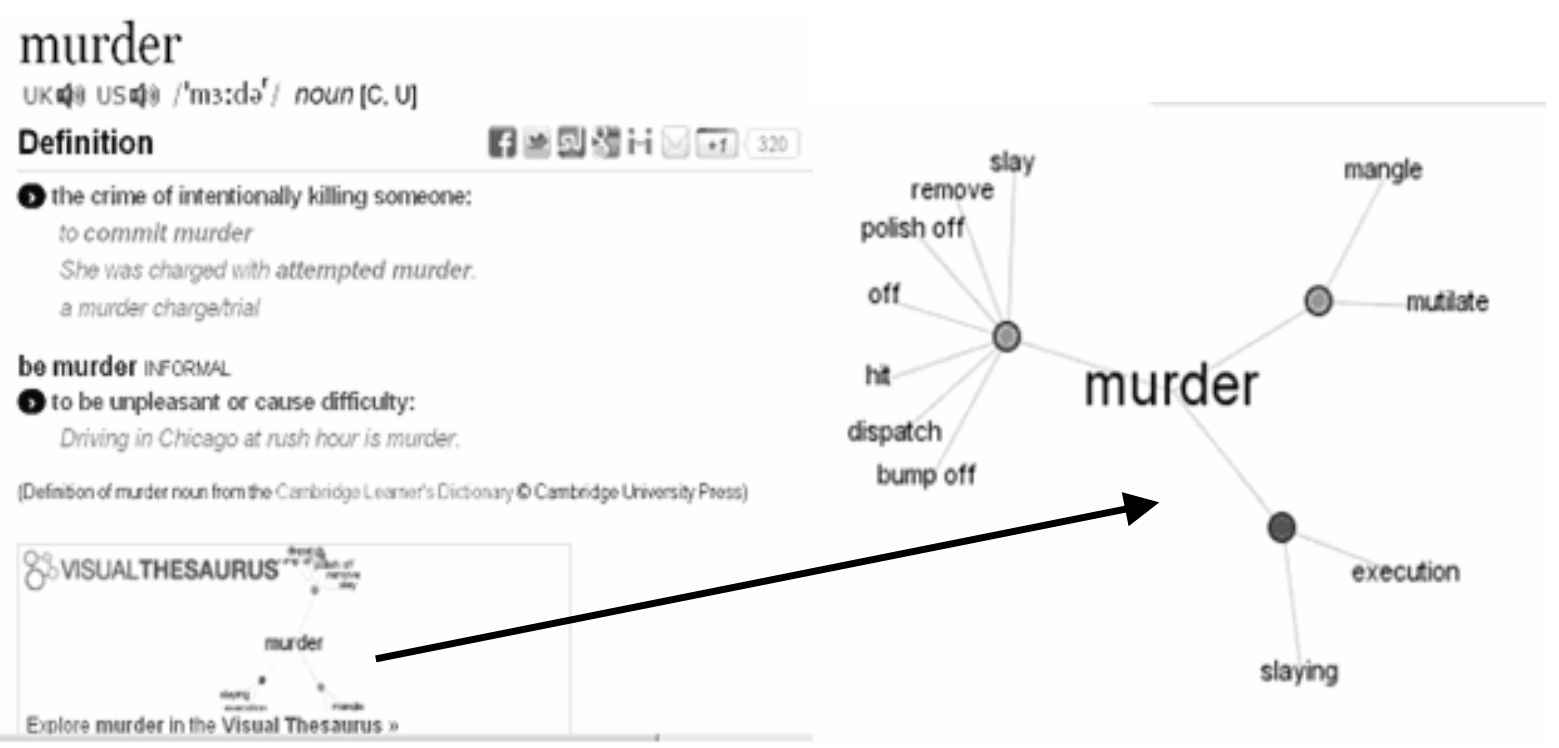

Fig. 1: Semantic relations at murder in e-CALD3

In general, electronic dictionaries feature immediate cross-reference, typically activated by a click of the mouse, in contrast to non-immediate cross-reference in dictionaries in book form, which, unlike pop-ups and other tooltips, may lead the dictionary user to lose sight of the original article (Lew in press). Electronic dictionaries are also very different from paper dictionaries as regards their outer and inner access structures, i.e. indicators which help dictionary users locate specific entries on the one hand, and those which guide them inside the entries to find the required information (Bergenholtz and Gouws 2007: 243). Getting to the desired entry in a paper dictionary may require scanning tediously numerous running heads. 
Dziemianko, Anna. 'On the use(fulness) of paper and electronic dictionaries.' In Granger, Sylviane and Magali Paquot (eds.), Electronic Lexicography. Oxford: Oxford University Press. Pre-publication draft. Not for quotation or copying.

By contrast, the outer access structure of electronic dictionaries is dramatically simplified. Typing in a word generally provides access to a list of relevant entries (e.g. 'issue' as a noun or verb) or opens up the appropriate entry directly (e.g. 'argument'). In that case, the user does not need to use the outer access structure (Bergenholtz and Gouws 2007: 244). Similarly, whereas paper dictionaries have only a linear, non-hierarchical microstructure, inasmuch as users cannot choose the amount of information made available to them, electronic dictionaries can offer a layered, hierarchical inner access structure. Electronic dictionaries are more flexible and dynamic: they can, for example, provide direct access to a specific definition followed by examples if the user selects a particular sense from the menu displayed at the top of the entry (Lew 2011; Tono 2000: 855). This type of layered presentation means that the amount of information displayed at a time is restricted: first, there is a concise overview of the senses explained in a specific entry, and once a sense is selected, the relevant information is shown either first or alone on screen on screen. The screenshot below illustrates the menu in the entry for business in MEDO.

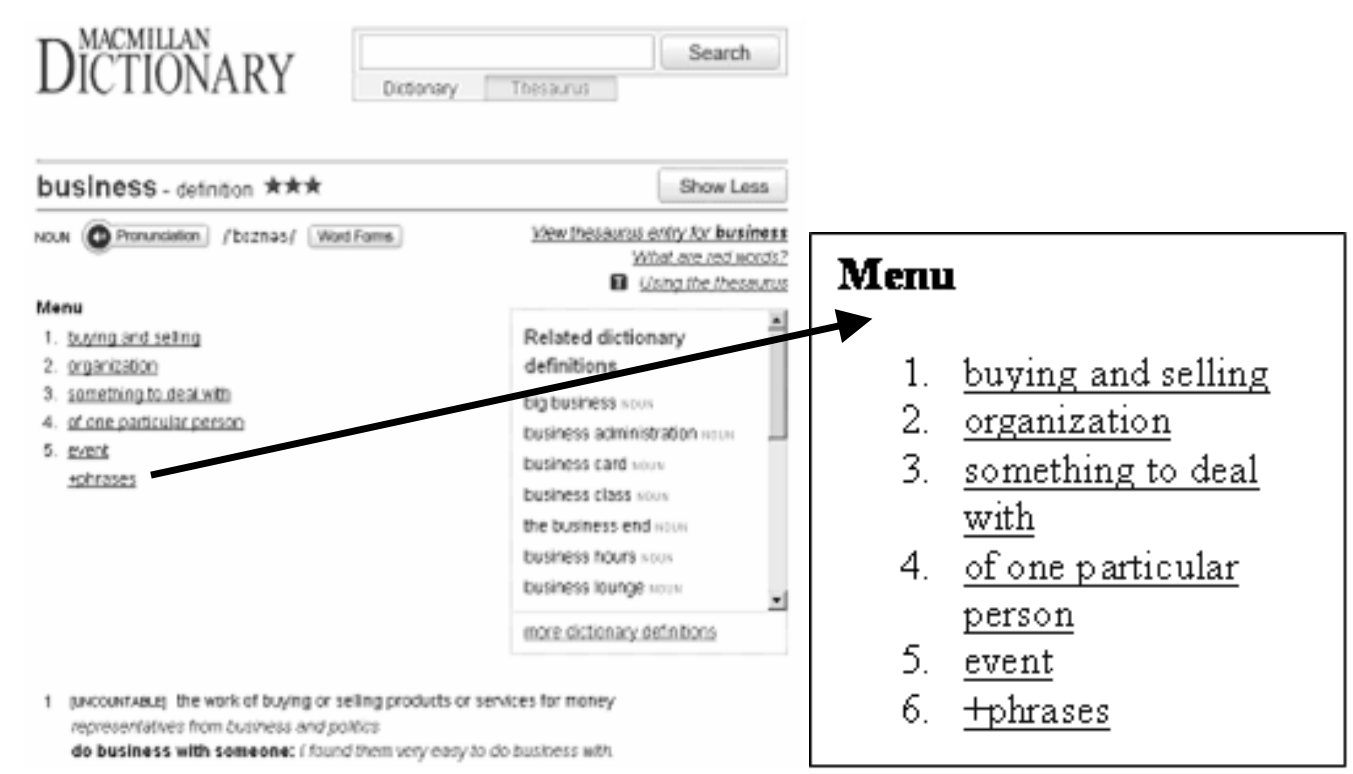

Fig. 2: Menu in the entry for business in MEDO

As a result of these differences in the amount of information and access functionality between paper and electronic dictionaries, the authority of paper dictionaries may be challenged, if not jeopardised (Zaenen 2002: 239). After all, it seems that bulky paper dictionaries may be easily superseded by multi-functional electronic dictionaries. Yet, electronic dictionaries are often regarded as inferior in quality (Chen 2010: 292, 295, Nesi, this volume, Tono 2009: 48). As Béjoint (2010: 375) observed, "[e]-dictionaries do not have the appearance, the binding, the thickness, the weight, the leather of the Bible, and they do not have the respectability either: anybody can produce an electronic document and change it immediately - literally - without anybody noticing." The bird's-eye-view of the whole page in a paper dictionary, which often makes it possible for dictionary users to spot, even inadvertently, all sorts of additional information, including pictures and text boxes, as well as the possibility of making notes and marking information on paper are sometimes considered 
Dziemianko, Anna. 'On the use(fulness) of paper and electronic dictionaries.' In Granger, Sylviane and Magali Paquot (eds.), Electronic Lexicography. Oxford: Oxford University Press. Pre-publication draft. Not for quotation or copying.

the crucial advantages of dictionaries in book form (Osaki et al. 2003: 205). It is only natural, then, that the tradition and reliability of paper dictionaries on the one hand, and the userfriendliness and convenience of electronic dictionaries on the other, pose questions about the relative usefulness of the two dictionary formats.

The aim of the chapter is to compare the use and usefulness of paper and electronic dictionaries in the light of findings from the pertinent research published in recent years (mainly 2000-2011). Studies involving robust-machine electronic dictionaries (stand-alone or networked) as well as handheld dictionaries such as PEDs are considered. Special attention is paid to the role of the medium in developing and altering patterns of electronic dictionary consultation as well as their effects on language reception, production and learning.

To discuss the role of dictionary form within the confines of a chapter, studies which rely mainly on the experimental method were chosen as points of reference. Naturally, the quantitative information obtained from experiments is often supported by qualitative analyses and judgments, which typically throw light on how dictionaries are perceived by users themselves. Surveys, questionnaires, interviews, observations and protocols are thus considered below as long as they perform an ancillary role and accompany experimentation. The selected studies are listed chronologically in Table 1 in the Appendix. Their main characteristics are described along four lines: task, number and types of subjects, methods of monitoring dictionary use, and testing users' familiarity with paper and electronic dictionaries.

The following section (Section 2) focuses on the usefulness of paper and electronic dictionaries in decoding and language production. Among other things, the effects of the medium on reading comprehension and finding contextually appropriate meaning are considered. The frequency and speed of dictionary consultation, as conditioned by dictionary format, are discussed in Sections 3 and 4, respectively. Selected changes in patterns of dictionary use and user behaviour as well as the consequences of the medium for inference and contextual guessing are also explored there. In Section 5, the depth of processing dictionary information on paper and on screen and its effects on language learning are discussed. An attempt is made to see whether dictionary users' involvement and retention of the information retrieved are inffluenced by dictionary form. Subjective opinions of both paper and electronic dictionaries are summarised in Section 6. Considering the wide range of the studies reviewed, comparability problems and research limitations are acknowledged in Section 7. Suggestions for further research, presented in Section 8, conclude the chapter.

\section{Dictionary consultation for decoding and encoding purposes}

One of the earliest publications concerned with language reception with the help of existing paper and electronic dictionaries was authored by Nesi (2000b). In her study, two texts had to be read and understood, one with access to OALDCE5 in book form and the other using the same dictionary on CD-ROM. Nesi (2000b: 111) concludes that there were no statistically significant differences in comprehension scores between the two dictionary conditions. Two versions of the same dictionary (COBUILD6 on paper and on the internet) were also employed in the experiment conducted by Dziemianko (2010). In the decoding task, subjects had to explain the meaning of nine English nouns and phrases. In stark contrast to Nesi's (2000b) findings, the results suggest that the electronic dictionary was significantly more useful in this respect than the paper dictionary. More precisely, the proportion of correctly explained target items was significantly higher in the electronic-dictionary condition than in 
Dziemianko, Anna. 'On the use(fulness) of paper and electronic dictionaries.' In Granger, Sylviane and Magali Paquot (eds.), Electronic Lexicography. Oxford: Oxford University Press. Pre-publication draft. Not for quotation or copying.

the paper-dictionary condition. It is important to note that in this study, the contrast between decoding and encoding reflects the distinction drawn by Laufer and Goldstein (2004: 405-406) between passive and active knowledge: the ability to supply the meaning of a given word form is passive knowledge (necessary for decoding), while the ability to supply the word form for a given meaning is active knowledge (necessary for encoding).

Studies which investigated the use of electronic dictionaries on hand-held devices, rather than on CD-ROMs or the internet, have also yielded divergent conclusions. Osaki et al. (2003) set out to investigate the role of dictionary form (paper and PEDs) in accessing the meaning of target words underlined in a text as well as in reading comprehension. It turned out that pocket electronic dictionary consultation significantly facilitated choosing a contextually appropriate meaning and resulted in better comprehension scores than reference to the paper dictionary. The subjects using the electronic dictionary spent much less time searching for the target vocabulary items than those consulting the paper dictionary (see Section 3). Possibly, the time saved by using the electronic dictionary enabled the students to process the context of the passage in more depth, which, in turn, increased their accuracy in looking for contextually appropriate meanings. Quick access to the information in the electronic dictionary may also have meant less interference in the process of reading, hence the better comprehension scores (Osaki et al. 2003: 210). Osaki and Nakayama (2004, cited in Koyama and Takeuchi 2007: 111) obtained broadly similar findings when they compared the role of dictionary form in text comprehension and identification of the contextually appropriate meaning of target lexical items. The results show that pocket electronic dictionaries were more useful in locating the relevant meaning, and their consultation led to better text comprehension than reference to paper dictionaries.

However, less optimistic findings follow from the studies by Koyama and Takeuchi (2007), Chen (2010) and Kobayashi (2007), who also investigated the use of electronic dictionaries available on hand-held devices. On the basis of two reading tasks, Koyama and Takeuchi (2007) conclude that reference to such electronic dictionaries contributes next to nothing to reading comprehension. Yet, as the authors themselves note, their investigations were limited, considering the small number of participants (around 30 in each study) and, consequently, poor reliability of statistical tests. In the comprehension part of the study by Chen (2010), in which choice had to be made between the suggested meaning explanations of selected infrequent words, no substantial effect of dictionary form on sense selection or vocabulary comprehension was identified. Kobayashi (2007: 659), who relied on both qualitative and quantitative methods (i.e., a questionnaire and a reading task), did not observe any statistically significant differences in reading comprehension scores between paper and pocket electronic dictionary conditions, either.

When considering meaning identification tasks, it is also worth paying attention to empirical studies which employ specifically designed consultation tools, rather than any existing paper and electronic dictionaries. In a recent study, Tono (2011) made use of the eyetracking method to monitor the process of electronic dictionary lookup and investigate how users search for word meaning in a dictionary entry. Instead of using a real dictionary, special microstructures for the words make and fast were created based on LDOCE5 and MEDO, respectively. To investigate how guiding devices such as menus and signposts affect users' look-up processes, dictionary entries were then modified to produce entries with and without these features. Tono (2011: 148) observed that his subjects made almost no use of signposts, i.e. "sense indicators given at the beginning of each sense" (Lew and Tokarek, 2010: 194), such as those shown in the following screenshot of the e-LDOCE5 entry for the adjective fast (i.e. MOVING QUICKLY, IN A SHORT TIME, CLOCK, COLOUR, SPORTS). 
Dziemianko, Anna. 'On the use(fulness) of paper and electronic dictionaries.' In Granger, Sylviane and Magali Paquot (eds.), Electronic Lexicography. Oxford: Oxford University Press. Pre-publication draft. Not for quotation or copying.

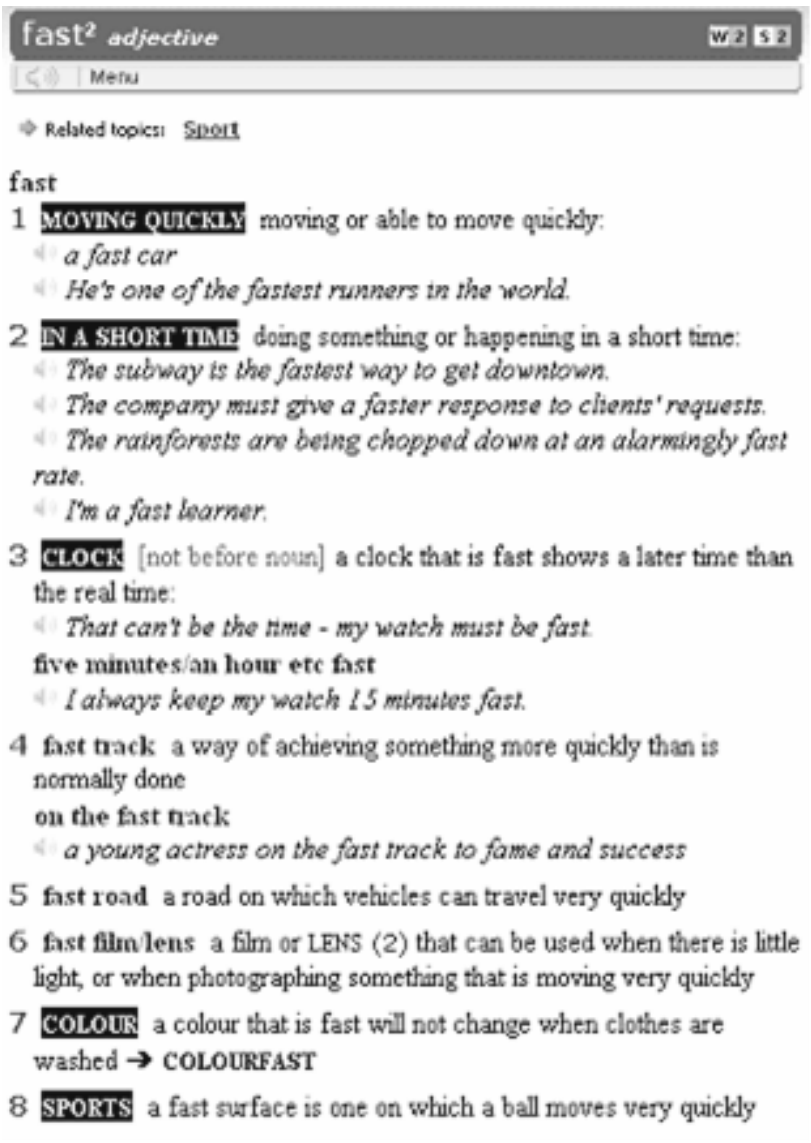

Fig. 3: Signposts in the entry for fast in e-LDOCE5

Admittedly, more proficient students used signposts more than less proficient ones, who took virtually no notice of this navigation tool, presumably because they did not understand its function. All the participants were sometimes misled by the oversimplified word meanings conveyed by signposts and obtained worse results in locating the relevant sense of make in entries with signposts than in those without them. Menus, in turn, facilitated access to the relevant sense of fast for less proficient subjects, but were largely ignored by the more advanced students (Tono 2011: 136, 150).

To some extent, Tono's (2011) findings concerning menus resemble the conclusions drawn by Lew and Tokarek (2010). In their study study, learners were asked to complete partial English translations of Polish sentences with the help of an experimental (twenty-entry) Polish-English online dictionary, created in three different versions and assigned randomly to subjects. The versions differed in the way entries could be navigated by dictionary users to test the usefulness of entry menus as access facilitators in online bilingual dictionaries. The first version displayed complete entries with no menu. In the second version, the user was first presented with a menu of senses; once the user clicked on a specific sense, the full entry, automatically scrolled to the clicked sense, appeared. The third version was identical to the second, except that the target sense was also highlighted. It was found that, as in the study by Tono (2011), bare menus helped lower-level students to access the right sense, but were a hindrance to higher-level users. By contrast, menus with highlighting proved comparably helpful to users at both levels.

These findings, however, differ from the results of studies that focus on guiding devices in paper dictionaries. Nesi and Tan (2011), for example, compared three versions of 
Dziemianko, Anna. 'On the use(fulness) of paper and electronic dictionaries.' In Granger, Sylviane and Magali Paquot (eds.), Electronic Lexicography. Oxford: Oxford University Press. Pre-publication draft. Not for quotation or copying.

entries for a selected list of high-frequency words in MEDAL2: (1) with their original menus as available in MEDAL2, (2) without any guiding device, and (3) in a new format where menu information was dispersed as signposts or shortcuts within the entry. They found no significant difference in the time participants took to select word senses in entries with or without guiding devices, be they menus or signposts. Menu use did not yield significantly more accurate sense selections, and there was no significant difference between the scores for menus and the scores for shortcuts. However, a significant difference between the scores for signposts and the scores for entries without any guiding device was found, which led Nesi and Tan (2011) to conclude that signposts are a more effective navigation tool than menus. This view is supported by Lew's (2010b) findings. In his experiment, students had to complete partial English translations of six English sentences with the help of English words for which paper-based dictionary entries were supplied. Half of the participants had access to unmodified OALDCE7 entries featuring signposts or shortcuts. The other half worked with modified OALDCE7 entries, in which the original shortcuts were converted into entry-initial menus. Lew (2010b: 1125-1126) concluded that "shortcuts-equipped entries lead to significantly better translations, and the accuracy with which Shortcuts users identified the relevant senses was $15 \%$ higher (though not significantly so) than for those using Menus. These findings point to an advantage of Shortcuts, a distributed cues system (also known as Guidewords or Signposts), over a single entry-initial Menu."

Overall, signposts seem to be more effective than menus in facilitating sense identification in paper dictionaries (Lew 2010b, Nesi and Tan 2011), but not in electronic applications (Tono 2011). However, simple menus in entries displayed on the computer screen, either clickable or not, are typically appreciated by less proficient subjects (Lew and Tokarek 2010, Tono 2011), but they do not prove helpful in paper-based entries (Lew 2010b, Nesi and Tan 2011). This suggests that the effectiveness of guiding devices may depend not only on their type (shortcuts vs. menus; clickable menus or not), but also on the medium in which they are used (paper, electronic) and the proficiency of dictionary users.

Compared to the number of studies that analyse dictionary use for decoding purposes, there are very few that investigate the use of electronic dictionaries for encoding purposes. Chen (2010) asked subjects to compose sentences with the low-frequency target words whose correct meaning explanations had to be identified in the comprehension task described above. The sentences produced by the subjects had to be different from any examples provided in the paper and electronic dictionaries which they consulted. If a composed sentence was semantically, grammatically and pragmatically correct, two points were scored; if it was only semantically correct (but grammatically incorrect or pragmatically inappropriate), only one point could be gained. Framing semantically incorrect sentences or confusing the grammatical category of the target words resulted in no points. The study showed no marked effect of dictionary form on production; the scores were comparable irrespective of whether the subjects used paper or portable electronic dictionaries. Such results stand in stark contrast to those obtained by Dziemianko (2010), although, admittedly, in a different encoding task, in which subjects had to complete sentences with the right prepositions removed from collocations (e.g. on the blink, wreak havoc on or at gunpoint) with the help of the paper or online versions of COBUILD6. To make sure that the participants could not rely on their knowledge of English, a pre-test was run, in which the same task had to be done without access to any dictionary. The cases where the students make do without consulting a dictionary were eliminated from further analysis. The accuracy of the subjects' responses was significantly better in electronic dictionary conditions. 
Dziemianko, Anna. 'On the use(fulness) of paper and electronic dictionaries.' In Granger, Sylviane and Magali Paquot (eds.), Electronic Lexicography. Oxford: Oxford University Press. Pre-publication draft. Not for quotation or copying.

\section{Speed of dictionary consultation}

Speed is seen as one of the main advantages of using electronic dictionaries, in particular those on portable devices, but also those online and on CD-ROMs (de Schryver 2003, Prinsloo 2005, Stirling 2003, Tang 1997, Tono 2000). In a study whose objective was "purely look-up speed; i.e. how quickly students could find the definition(s) of an unknown word" (Weschler and Pitts 2000), students looked up words 23 percent faster with a portable electronic dictionary than with a paper one. Yet, look-up time was measured manually and the students were not requested to read, let alone understand, the explanations of the words checked. Weschler and Pitts (2000) concluded from the information elicited from their subjects in the accompanying questionnaire that while such a speed difference could be a decisive factor in $\mathrm{L} 2$ reception, almost none of the respondents could benefit from it when speaking, as consultation of portable dictionaries would still be too time-consuming to be practicable. Optimistic results concerning look-up time were also achieved in studies into portable electronic dictionary use conducted by Koyama and Takeuchi (2007: 118): portable electronic dictionaries were found to considerably reduce the time needed to read a passage in English, which was attributed to their superior search functions. Likewise, Chen (2010: 301) noted that consulting pocket electronic dictionaries was much less time consuming than making use of paper dictionaries, and observed that it takes considerably less time to complete the same vocabulary exercise when working with PEDs than with paper dictionaries.

However, there is also research which does not confirm the advantage of hand-held electronic dictionaries with respect to consultation speed. In the reading comprehension and vocabulary exercises in the studies by Koyama and Takeuchi $(2003,2004)$, the time needed to perform vocabulary search in paper and portable electronic dictionaries was comparable. The authors put this result down to the additional work that the subjects in the electronic dictionary condition had to do, such as pushing one button after another in the case of some words or scanning the different screens to spot the necessary information, whereas in the paper dictionary all the information was usually available on the same page (Koyama and Takeushi 2004: 36). In addition, Koyama and Takeuchi (2004) observed that there was no difference between the two dictionary conditions in the time needed to access examples. Likewise, Shizuka (2003) found that dictionary format had no significant effect on the speed of getting to usage information in examples; the information proved to be no easier to extract from the portable electronic dictionary than from the paper one, the hierarchical nature of data display in the former notwithstanding. Such a conclusion follows from the second part of Shizuka's (2003) experiment, intended to throw light on the speed with which specific usage information was located in the numerous examples of take, bring, have, go, keep, give, put, make, get and come. This part of the experiment aimed to test the functionality of the hierarchical information display in the portable dictionary, where examples of usage could be accessed by clicking a button next to the relevant meaning, as opposed to one-level display in the paper dictionary, where all the information could be seen at the same time.

As regards stand-alone robust-machine electronic dictionaries, positive results on look-up time were obtained by Tono (2000), who tested the usefulness of three interfaces (i.e. traditional, parallel and layered) against paper dictionary (control) conditions. The task consisted in identifying acceptable translation equivalents of the looked-up words, and the speed of finding the relevant information was taken to reflect look-up ease (Tono 2000: 857). In the traditional interface, information was displayed as in a paper dictionary, with idioms and phrasal verbs listed at the end of the entry. In the parallel interface, information was 
Dziemianko, Anna. 'On the use(fulness) of paper and electronic dictionaries.' In Granger, Sylviane and Magali Paquot (eds.), Electronic Lexicography. Oxford: Oxford University Press. Pre-publication draft. Not for quotation or copying.

shown in a parallel bilingual translation format: all the words as well as idioms and other multi-word expressions were accorded separate entries with translations in parallel format. In the layered interface, by contrast, the information was organised by a tab menu, where each tab offered more information than the previous one (Tono 2000: 857). It turned out that access to target entries was quicker in the electronic dictionary, irrespective of the interface.

However, the largest difference between the paper and electronic dictionary conditions occurred with the parallel interface. As regards the effect of electronic dictionary interface, Tono (2000: 859-860) concluded that the parallel interface ensures much faster searches than the traditional or layered interfaces.

The superiority of stand-alone robust-machine electronic dictionaries over paper ones with respect to consultation speed was not confirmed by Nesi (2000b: 111), who, as already mentioned, investigated the usefulness of paper and CD-ROM versions of OALDCE5 and made note of the time each subject took to complete the experiment. No significant differences in time between the two experimental conditions were observed. Yet, it should be stressed that it is not the time of single look-ups that was measured, but the time needed to complete the reading task as such.

\section{Number of lookups}

While the above conclusions concerning the relative speed of paper and electronic dictionary use are quite diverse, the results of studies into the number of look-ups are more uniform. The electronic medium was usually found to stimulate more frequent dictionary consultation, in particular when hand-held dictionaries were used (Kobayashi 2007, Koyama and Takeuchi 2003, 2007, Osaki et al. 2003). ${ }^{1}$

Most observations concerning off the number of look-ups were made in studies that investigated dictionary use in reading comprehension. These studies suggest that electronic dictionaries, especially PEDs, entail very different dictionary consultation patterns. Kobayashi (2007), for example, found that the availability of pocket electronic dictionaries made the subjects almost immediately look up any words which were problematic and prevented them from trying to recall the words or guessing what they meant. By contrast, paper dictionaries deferred dictionary consultation: the subjects read the full text once and looked up the meaning of doubtful or unfamiliar words in dictionaries in book form only at second reading. Delayed dictionary consultation stimulated guessing and inferring the meaning of unknown words from the context. Kobayashi (2007: 666) thus concluded that PEDs may not benefit all users, especially less proficient ones, since frequent dictionary consultation means less interaction with the text. When reading a passage with the help of readily available electronic dictionaries, in particular PEDs, the most immediate concern of language learners is finding the translation of the words looked up rather than understanding the whole passage (see also Tang 1997: 46). As a result, such dictionary users may operate at the level of individual words, rather than discourse (see Stirling 2003).

These findings are further supported by those of Tono (2009: 58), who maintains that constant recourse to electronic dictionaries might be problematic, since learners may grow too impatient and refer to a dictionary any time they feel in doubt while reading. What they should do, in his view, is contextual guessing - they should try to form a preliminary guess on the basis of the context and only then verify it against dictionary information. Such initial assumptions are important inasmuch as they facilitate search for the right meaning in a 
Dziemianko, Anna. 'On the use(fulness) of paper and electronic dictionaries.' In Granger, Sylviane and Magali Paquot (eds.), Electronic Lexicography. Oxford: Oxford University Press. Pre-publication draft. Not for quotation or copying.

dictionary. Immediate recourse to a dictionary in the process of reading, encouraged by the speed and ease of electronic dictionary use, may discourage learners from making contextual guesses and, in fact, hinder effective dictionary consultation; learners may be less successful in getting to the sense appropriate for a given context.

However, Koyama and Takeuchi (2007) showed that reading comprehension remains largely unaffected by the increased frequency of dictionary consultation stimulated by the electronic medium. They also found that PEDs encourage learners to look up more words irrespective of their prior knowledge of the vocabulary. Given access to such dictionaries, learners willingly rechecked the words they thought they knew (Koyama and Takeuchi 2007: 115-116). Apparently, electronic dictionaries on hand-held devices make learners less wary of dictionary use.

It is not clear whether robust-machine (stand-alone or networked) electronic dictionaries benefit users in the same way. This might be true if the text being read is in electronic form as well. If it is on paper, decisions about using dictionaries installed on the computer or available online, but accessed through the computer, might be different, since turning attention from paper to screen is no doubt an additional effort. Admittedly, the study by Nesi (2000b), discussed above, which involved the use of paper and CD-ROM versions of one dictionary in reading a paper-based text showed that the difference in the number of lookups between the two experimental conditions, although still in favour of the electronic dictionary, was not statistically significant. Nonetheless, it appears that more research is needed to shed light on the effect of electronic dictionaries accessed through robust machines on look-up patterns. More attention should also be paid to task operationalisation and dictionary format.

\section{Learning}

Vocabulary learning is admittedly not an immediate or typical goal of dictionary use, but rather a "by-product of dictionary consultation" (Lew and Doroszewska 2009: 240). Many studies, however, have investigated the impact of paper vs. electronic dictionaries on word retention. Empirical research most often shows that the dictionary medium (paper vs. electronic) does not have a significant bearing on learning words (Chen 2010, Kobayashi 2007, Koyama and Takeuchi 2003, Osaki et al. 2003, Osaki and Nakayama 2004, Xu 2010). However, Koyama and Takeuchi (2004) found that reference to a paper dictionary resulted in much better vocabulary retention than the consultation of a PED. By way of explanation, they pointed out that accessing the right entry in paper dictionaries is typically an arduous and elaborate task, whereas in electronic dictionaries it usually boils down to inputting the spelling of the headword. Thus, the more demanding process of finding information in a dictionary in book form might pave the way for better retention (Koyama and Takeuchi 2004: 42).

Koyama and Takeuchi's (2004) results are in line with the Involvement Load Hypothesis, whereby investing greater mental effort in attaining information can pay off in better retrieval and recall than obtaining information with less intellectual effort (Laufer and Hulstijn 2001; Hulstijn and Laufer 2001). In other words, the retention of new words is contingent on the depth of processing: the deeper the processing is, the better the chances of remembering the new vocabulary are (Hulstijn and Laufer 2001: 545). Tono (2009: 64) suggested that easy access to electronic dictionaries cannot help this process. In his view, 
Dziemianko, Anna. 'On the use(fulness) of paper and electronic dictionaries.' In Granger, Sylviane and Magali Paquot (eds.), Electronic Lexicography. Oxford: Oxford University Press. Pre-publication draft. Not for quotation or copying.

lexical information can be processed more deeply and learned better if paper dictionaries are used, because such dictionaries, unlike electronic ones, make it possible for their users to mark, underline or otherwise highlight the information that is important to them in the microstructure.

Not all studies of dictionary use, however, seem to confirm the Involvement Load Hypothesis. The results obtained by Dziemianko (2010: 262), for example, show that using an electronic dictionary can lead to better retention of both meaning and collocations. It turns out that is not so much the effort put into the extraction of relevant information from the dictionary on paper as the saliency of an entry on the computer screen and, surprisingly, the ease of look-up that prove beneficial to learning (Dziemianko 2010: 266). The difficulty of paper dictionary use may actually put off language learners, who might be confused, if not overwhelmed and annoyed, by the wealth of information not immediately relevant to the task at hand, which they are nonetheless bound to note and wade through. However, such conclusions do not undermine the main tenet of the Involvement Load Hypothesis (Laufer and Hill 2000: 72). The question is what warrants attention. In fact, a demanding look-up process does not have to merit attention; it might rather provoke irritation and anxiety. In other words, attention does not necessarily correlate with the effort put into dictionary look-up, which is often performed quite automatically. Instead, the conspicuousness of headwords and entries on the computer screen might arrest users' attention, which, unlike in the paper dictionary, is not dispersed by other headwords crammed onto the same page (Dziemianko 2010: 265). ${ }^{2}$

Craik and Tulving (1975: 268) point out that the persistence of a memory trace is "a positive function of 'depth' of processing, where depth refers to greater degrees of semantic involvement." Pattern recognition and meaning extraction, however, are usually preceded by a preliminary analysis of stimuli, i.e. an "analysis of such physical or sensory features as lines, angles, brightness, pitch, and loudness" (Craik and Lockhart 1972: 673). Since human beings are concerned primarily with meaning extraction from stimuli, they tend to store products of deeper semantic and cognitive involvement, rather than those of any preliminary stages. It is therefore possible to venture a statement that, in the process of paper dictionary consultation, turning pages and wading through a large number of entries on the same page to finally track down an entry corresponds to the preliminary stages of analysis described by Craik and Lockhart (1972). These initial stages of paper dictionary look-up do not necessarily contribute to better retention or strengthening the memory trace, as they do not necessitate semantic involvement. All in all, it might be suggested that it is not any involvement that matters to vocabulary retention in the process of dictionary use, but semantic involvement. Consequently, the largely automatic stages of paper dictionary look-up which precede processing the information found in the relevant entry might not induce sufficient semantic and cognitive involvement in dictionary users to positively affect retention.

On the other hand, Shizuka (2003: 32) claimed that greater look-up frequency, typical of electronic dictionaries, especially portable ones, might benefit dictionary users. Koyama and Takeuchi's (2004: 41) findings, however, indicate that, in reality, task-induced involvement may be more important than look-up frequency alone, which does not warrant better retention. ${ }^{3}$ Similarly, Lew and Doroszewska (2009: 259) argued that "retention rates do not seem to be affected by the sheer amount of dictionary activity. (...) it is the quality rather than the quantity of lookups that makes a real difference: not how many, but which entry components are being consulted." In their study, subjects had to read an online text with ten difficult words highlighted. For each of the words, a dictionary entry was created with four possible types of information: English definition, Polish equivalent, animated picture and examples of usage. The entry appeared as a menu, and the subjects could choose which 
Dziemianko, Anna. 'On the use(fulness) of paper and electronic dictionaries.' In Granger, Sylviane and Magali Paquot (eds.), Electronic Lexicography. Oxford: Oxford University Press. Pre-publication draft. Not for quotation or copying.

information type they wished to see. In the immediate (unexpected) retention test that followed, the subjects were asked to explain the meaning of each target word either in Polish or in English. Lew and Doroszewska (2009: 253) found that retention rates resulting from reference to animations were surprisingly low, only about half as good as for the other lookup options, even though animations were the second most often consulted source of information (after Polish equivalents). The difference in retention scores thus did not result from the amount of dictionary activity but from the type of lexicographic data consulted. The authors suspect that the failure of their animations to stimulate better retention might, among other things, stem from the transience of the video sequences or the fact that the animations distracted the students from form-meaning associations, which are a prerequisite for successful retention (Lew and Doroszewska 2009: 253-254).

\section{Appreciation}

Search speed and ease of use rank high among the features which are most appreciated in electronic dictionaries (Kobayashi 2008, Koyama and Takeuchi 2003, Nesi 2000b, Tang 1997, Tseng 2009). Almind (2005: 39) maintains that the speed of data retrieval from electronic dictionaries, coupled with search precision, "is the reason why even internet dictionaries with sub-standard content are successful." Portability, in turn, means that any bilingual dictionary on a hand-held device can act as an "umbilical cord" linking users to their mother tongue and boosting their confidence in L2 (Stirling 2003). The ease of use and speed of electronic dictionary consultation suggest that they can lower the consultation trigger point, i.e. the moment when foreign language learners decide to refer to a dictionary for the meaning of unknown words and phrases (Shizuka 2003: 32). Aust, Kelley, and Roby (1993: 70) found that readers consult hyper references much more willingly than comparable conventional (paper) references. They concluded that hyper references make learners less wary of dictionaries and help them to consult dictionaries more readily.

While such an effect has been attested for PEDs (Shizuka 2003: 27, 32), robustmachine electronic dictionaries have been found to encourage browsing in no way related to the task at hand (Nesi 2000b: 111). Such lateral browsing, already observed by Guillot and Kenning (1994: 72-73), is no doubt facilitated by hyperlinking whereby another dictionary entry is simply called up by double clicking a word on the screen or hovering the mouse over a word. It is thanks to such immediate cross-references that "looking up takes a whole new meaning in electronic dictionaries: laborious page-turning and letter hunting can be replaced with a single mouse click or even hovering your mouse over the target, whereupon a small popup window can display an instant explanation" (Lew 2010a: 391). No wonder, then, that words which are in no way connected with the text being read are willingly looked up in electronic dictionaries.

Overall, it appears that electronic dictionaries in any format have gone a long way towards reducing lexicographic information costs, i.e. "the difficulty, or inconvenience, that the user of a dictionary believes or feels is associated with consulting the dictionary" (Nielsen 1999: 111), and more specifically, search-related lexicographic costs, i.e., costs connected with look-up act (Nielsen 2008: 173). The electronic medium has relieved users of timeconsuming activities such as turning pages, scanning long columns crammed with information and deciphering phonetic transcription. Immediate cross-references, intuitive interfaces and partial or expandable entries make electronic dictionaries even more convenient and search- 
Dziemianko, Anna. 'On the use(fulness) of paper and electronic dictionaries.' In Granger, Sylviane and Magali Paquot (eds.), Electronic Lexicography. Oxford: Oxford University Press. Pre-publication draft. Not for quotation or copying.

cost-effective. Nonetheless, there is always the other side of the coin. Admittedly, the hierarchical display in the form of either clickable menus, where each match is hyperlinked to a subentry, or partial entries, and where the top of each match is displayed with a link to the full content of each lemma, gives a concise overview of search term matches, in contrast to the linear, much more overwhelming layout of paper dictionaries. Yet, extra search-related information costs emerge, such as additional clicking or scrolling, which might negatively affect the readiness to look up words in electronic dictionaries. That said, electronic dictionaries are no doubt much more (search-)cost-effective than those on paper.

Paper dictionaries, however, tend to be considered better learning tools than PEDs (e.g. Chen 2010). Traditional paper dictionaries are usually described as more detailed, accurate and reliable, notwithstanding the fact that they are cumbersome to carry as well as timeconsuming to consult. Surprisingly enough, the portable electronic dictionary used in Koyama and Takeuchi's (2003: 72) experiment was thought to provide insufficient information for language learning, even though the information was the same as in the paper dictionary employed in the study. Koyama and Takeuchi ascribed this assessment to the layered interface design of the PED: the small screen, a trade-off for portability, makes it possible to display only limited information and "might oblige students to push one button after another to obtain further information about the target word" (Koyama and Takeuchi 2003: 73, see also Yamada 2011). PEDs are also often criticised for the limited range of meanings and paucity of examples they display (Koyama and Takeuchi 2004, Stirling 2003). Kobayashi (2008), for example, found that pocket electronic dictionary users mainly complain about a dearth of varied examples (39\%), insufficient grammatical information (32\%), lack of information on usage $(27 \%)$, a small screen (19\%) and a relatively limited wordlist (16\%). Other downsides of portable electronic dictionaries include no room for notation, high cost and short battery life. It is possible, however, that some of these criticisms relate not so much to the medium per se as to the dictionaries consulted on portable devices, which may turn out to be less exhaustive than those loaded on robust-machine dictionaries.

Indeed, most of the criticisms levelled at PEDs do not usually apply to robust-machine dictionaries such as CD-ROM dictionaries or online dictionaries. These are typically accessed on computers with large screens that make it possible to present elaborate lexicographic information for all headwords. They are usually available for a limited fee (if not completely free), include a number of customisable or bottom-up editing features (Carr 1997: 214, Lew 2011) and often offer the possibility of making notes, a feature traditionally associated only with the paper medium.

\section{Comparability issues and the limitations of current research}

The question of the relative usefulness of paper and electronic dictionaries does not have a simple answer. As shown in Table 1, the studies reviewed here investigated dictionary use on the basis of many different tasks. In most cases the subjects had to carry out receptive tasks, which might give a deceptive impression of comparability. However, the tasks differed widely in design, which must have affected the results. The type of method used to evaluate comprehension ranges from true or false or open ended text comprehension questions to vocabulary questions focusing on meaning or synonyms. Some studies require subjects to look up low-frequency words, while others make them find the appropriate meaning of highly polysemous verbs. Most studies focused on single words but others also dealt with 
Dziemianko, Anna. 'On the use(fulness) of paper and electronic dictionaries.' In Granger, Sylviane and Magali Paquot (eds.), Electronic Lexicography. Oxford: Oxford University Press. Pre-publication draft. Not for quotation or copying.

collocations and other phraseological units. More problematically, perhaps, the results of studies that compare the use of paper and electronic dictionaries may be debatable when the paper and electronic dictionaries used do not share the same lexicographic features (e.g. coverage, layout and amount of information offered at the microstructural level as well as the way in which the information is presented typographically).

The studies reviewed here covered a cross-section of the world's population (e.g. EFL students in a British university, Polish students, Japanese students). Naturally, the subjects' dictionary-using habits and skills must have been affected by their native, cultural and linguistic backgrounds. No less important role was played by their education and proficiency in English. ${ }^{4}$ The wide spectrum which the participants represented in these respects must have had a bearing on the outcome of the research. In addition, the number of participants in the studies ranged from 5 (Tono 2011) to 781 (Weschler and Pitts 2000), and sampling procedures are typically not specified, although most subjects seemed to be university students who were accessible to the authors or their assistants. In the majority of cases the samples were relatively small, which means that they may not have been representative. Hasty generalisations drawn on this basis may be unreliable and invalid (Tarp 2009: 290-292). In fact, reaching conclusions about electronic dictionary usefulness is severely constrained when the types of user and usage situations are not clearly defined, lexicographic functions and data are not specific enough, and the ease or difficulty with which the data can be accessed and understood is not explained. Unfortunately, much too often such information is not divulged by researchers.

Table 1 also shows that many tools were employed to monitor dictionary consultation, including cutting-edge technology in the form of eye-tracking systems (Tono 2011, see Simonsen 2011). It remains to be seen whether this is the beginning of a new direction in which research into dictionary use will develop. It is nonetheless regrettable that so few researchers have made use of much less complicated log files, with the help of which electronic dictionary consultation can be unobtrusively studied in a natural setting, without the need to manipulate variables (de Schryver and Joffe 2004: 194). Finally, the table reveals insufficient interest in the subjects' previous experience of dictionary use. Even when it was considered a possible variable, it was typically assessed on the basis of the subjects' perception of their habits and skills, rather than any objective evaluation thereof. Testing actual paper- and electronic-dictionary literacy, rather than relying on assertions, beliefs or feelings, might give a more accurate picture.

\section{Conclusion}

To expect great uniformity across investigations into paper and electronic dictionary use would be overoptimistic, if not naïve. It is only natural that different authors strive to attain their own goals and answer their research questions using the methods which they consider appropriate. Yet, a few general suggestions for further research can be formulated by way of conclusion.

First, different users approach dictionary consultation in different ways and adopt their own strategies (Tono 2011). Unlike the book format, the electronic medium makes it possible to customise dictionaries and better adjust them to the individual needs of target users. In addition, it provides new and innovative technologies to get a deeper insight into what actually happens when users look up a word in a dictionary. Log files or eye-trackers, for 
Dziemianko, Anna. 'On the use(fulness) of paper and electronic dictionaries.' In Granger, Sylviane and Magali Paquot (eds.), Electronic Lexicography. Oxford: Oxford University Press. Pre-publication draft. Not for quotation or copying.

example, make it possible to computationally monitor all decisions made in the consultation process. These methods could also provide the information necessary to pave the way for further, or even immediate, improvements in electronic dictionary design (see de Schryver and Joffe 2004: 187).

Second, there is a need for comparative studies on the usefulness of various electronic dictionary types. Investigations into the relative usefulness of electronic dictionaries on CDROMs, PEDs and online dictionaries are virtually nonexistent. Some of the conclusions drawn above about the possible role of electronic dictionary formats seem speculative and should be treated as hypotheses which need to be verified by empirical studies. There is also room for more comparative research into the usefulness of paper and electronic dictionaries. It might be interesting to see whether there is indeed a positive correlation between the effort invested in (paper and electronic) dictionary search and vocabulary retention, or between the number of words looked up and reading comprehension. It is necessary, however, to distinguish the effort which is mainly cognitive or mental from the exertion which is primarily physical or mechanical. It is not at all clear whether dictionary users' cognitive involvement is different depending on whether they are faced with paper or (various types of) electronic dictionaries. Importantly, any research into the relative usefulness of paper and electronic dictionaries should be designed so that the medium, rather than just presentation issues, can be shown to be the reason for any observed differences. This might create the need for fabricated, purpose-built dictionaries, or at least dictionary entries, which would be exactly parallel not only in content, but also, as far as possible, in interface or layout. It remains to be hoped that further research into the role of dictionary form will make it possible one day to answer the seemingly simple question: which dictionary is more useful - paper or electronic? Although this may appear a naïve question to ask, the above discussion shows that formulating a straightforward and precise answer on the basis of current, highly diversified research is anything but easy, if feasible at all. 
Dziemianko, Anna. 'On the use(fulness) of paper and electronic dictionaries.' In Granger, Sylviane and Magali Paquot (eds.), Electronic Lexicography. Oxford: Oxford University Press. Pre-publication draft. Not for quotation or copying.

\section{Appendix}

Table 1. A summary of the studies reviewed

\begin{tabular}{|c|c|c|c|c|}
\hline Authors & Task & Subjects & $\begin{array}{l}\text { Methods of } \\
\text { monitoring } \\
\text { dictionary } \\
\text { use }\end{array}$ & $\begin{array}{l}\text { Testing } \\
\text { familiarity } \\
\text { with PD and } \\
\text { ED }\end{array}$ \\
\hline Nesi $(2000 b)$ & $\begin{array}{l}\text { reading texts on paper } \\
\text { with the help of } \\
\text { OALDCE5 in book form } \\
\text { and on CD-ROM; true / } \\
\text { false comprehension } \\
\text { questions }\end{array}$ & $\begin{array}{l}29 \text { subjects, non- } \\
\text { native speakers } \\
\text { of English from } \\
\text { different } \\
\text { linguistic } \\
\text { backgrounds }\end{array}$ & record sheets & $\begin{array}{l}\text { orientation } \\
\text { session }\end{array}$ \\
\hline Tono $(2000)$ & $\begin{array}{l}3 \text { purpose-built } \\
\text { computer-based } \\
\text { electronic dictionary } \\
\text { interfaces: traditional, } \\
\text { parallel, layered; paper } \\
\text { (control) conditions } \\
\text { provided by } \\
\text { Kenkyusha's College } \\
\text { Lighthouse English- } \\
\text { Japanese Dictionary and } \\
\text { Shogakukan's } \\
\text { Progressive Japanese- } \\
\text { English Dictionary; } \\
\text { language tasks: } \\
\text { a) out of context: simple } \\
\text { look-up (single words / } \\
\text { derivatives / idioms and } \\
\text { compounds) } \\
\text { b) in context: translation } \\
\text { and reading } \\
\text { comprehension for a } \\
\text { paragraph reconstruction } \\
\text { task } \\
\text { c) receptive vs. } \\
\text { productive skills [L1-L2 } \\
\text { / L2-L1] }\end{array}$ & $\begin{array}{l}5 \text { Japanese EFL } \\
\text { students at } \\
\text { Lancaster } \\
\text { University }\end{array}$ & $\begin{array}{l}\text { recorded with } \\
\text { the help of } \\
\text { Microsoft } \\
\text { Camcorder }\end{array}$ & questionnaire \\
\hline $\begin{array}{l}\text { Weschler } \\
\text { and Pitts } \\
(2000)\end{array}$ & $\begin{array}{l}\text { looking up a list of } \\
\text { words in paper and } \\
\text { electronic dictionaries; } \\
\text { dictionaries used - } \\
\text { unknown }\end{array}$ & $\begin{array}{l}781 \text { first year } \\
\text { students at } \\
\text { Kyoritsu } \\
\text { Women's } \\
\text { University and } \\
\text { College }\end{array}$ & observation & $\begin{array}{l}\text { orientation } \\
\text { session, } \\
\text { show-of- } \\
\text { hands survey, } \\
\text { questionnaire }\end{array}$ \\
\hline
\end{tabular}


Dziemianko, Anna. 'On the use(fulness) of paper and electronic dictionaries.' In Granger, Sylviane and Magali Paquot (eds.), Electronic Lexicography. Oxford: Oxford University Press. Pre-publication draft. Not for quotation or copying.

\begin{tabular}{|c|c|c|c|c|}
\hline Authors & Task & Subjects & $\begin{array}{l}\text { Methods of } \\
\text { monitoring } \\
\text { dictionary } \\
\text { use }\end{array}$ & $\begin{array}{l}\text { Testing } \\
\text { familiarity } \\
\text { with PD and } \\
\text { ED }\end{array}$ \\
\hline $\begin{array}{l}\text { Koyama and } \\
\text { Takeuchi } \\
(\mathbf{2 0 0 3 )}\end{array}$ & $\begin{array}{l}\text { reading a text, } \\
\text { underlining the words } \\
\text { looked up and answering } \\
\text { ten comprehension and } \\
\text { vocabulary questions; } \\
\text { the Genius English- } \\
\text { Japanese Dictionary ( } 2^{\text {nd }} \\
\text { edition, Taishukan) in } \\
\text { book form and its } \\
\text { electronic version on } \\
\text { CASIO EX-word XD- } \\
2500 \text {; word recall and } \\
\text { recognition after one } \\
\text { week }\end{array}$ & $\begin{array}{l}42 \text { college and } \\
\text { high school } \\
\text { students, } 4 \\
\text { students in an } \\
\text { additional study }\end{array}$ & $\begin{array}{l}\text { video } \\
\text { recording, } \\
\text { think-aloud } \\
\text { protocols ( } 4 \\
\text { students) }\end{array}$ & $\begin{array}{l}\text { questionnaire, } \\
\text { free } \\
\text { comments }\end{array}$ \\
\hline $\begin{array}{l}\text { Osaki et al. } \\
(2003)\end{array}$ & $\begin{array}{l}\text { looking up } 15 \text { target } \\
\text { words (while reading) in } \\
\text { the paper version of the } \\
\text { Genius English- } \\
\text { Japanese Dictionary and } \\
\text { the electronic one on } \\
\text { EX-word XD-R8100 } \\
\text { from CASIO; } \\
\text { a ten-question } \\
\text { comprehension test; } \\
\text { immediate and delayed } \\
\text { vocabulary tests }\end{array}$ & $\begin{array}{l}\text { 167 Japanese } \\
\text { university } \\
\text { students divided } \\
\text { into upper and } \\
\text { lower proficiency } \\
\text { levels }\end{array}$ & unknown & unknown \\
\hline $\begin{array}{l}\text { Shizuka } \\
(2003)\end{array}$ & $\begin{array}{l}\text { choosing Japanese } \\
\text { synonyms for ten } \\
\text { monosemous English } \\
\text { nouns; completing } \\
\text { examples for highly } \\
\text { polysemous verbs } \\
\text { extracted from } \\
\text { dictionaries; Genius } \\
\text { English-Japanese } \\
\text { Dictionary on paper and } \\
\text { its electronic version on } \\
\text { XD-S1200 by CASIO }\end{array}$ & $\begin{array}{l}77 \text { Japanese } \\
\text { students }\end{array}$ & unknown & questionnaire \\
\hline
\end{tabular}


Dziemianko, Anna. 'On the use(fulness) of paper and electronic dictionaries.' In Granger, Sylviane and Magali Paquot (eds.), Electronic Lexicography. Oxford: Oxford University Press. Pre-publication draft. Not for quotation or copying.

\begin{tabular}{|c|c|c|c|c|}
\hline Authors & Task & Subjects & $\begin{array}{l}\text { Methods of } \\
\text { monitoring } \\
\text { dictionary } \\
\text { use }\end{array}$ & $\begin{array}{l}\text { Testing } \\
\text { familiarity } \\
\text { with PD and } \\
\text { ED }\end{array}$ \\
\hline $\begin{array}{l}\text { Koyama and } \\
\text { Takeuchi } \\
(\mathbf{2 0 0 4 )}\end{array}$ & $\begin{array}{l}\text { comprehending two } \\
\text { written texts without } \\
\text { recourse to a dictionary } \\
\text { and answering } \\
\text { vocabulary questions } \\
\text { with a paper dictionary } \\
\text { (text 1) and an electronic } \\
\text { dictionary (text 2); } \\
\text { Genius English- } \\
\text { Japanese Dictionary ( } 3^{\text {rd }} \\
\text { edition, Taishukan) in } \\
\text { book form and its } \\
\text { electronic version on } \\
\text { CASIO EX-word XD- } \\
8100 \text {; } \\
\text { word recall and } \\
\text { recognition after one } \\
\text { week }\end{array}$ & $\begin{array}{l}18 \text { undergraduate } \\
\text { university } \\
\text { students } \\
\text { (intermediate) }\end{array}$ & $\begin{array}{l}\text { individual } \\
\text { video } \\
\text { recording }\end{array}$ & $\begin{array}{l}\text { questionnaire, } \\
\text { free } \\
\text { comments }\end{array}$ \\
\hline $\begin{array}{l}\text { Osaki and } \\
\text { Nakayama } \\
(2004)\end{array}$ & $\begin{array}{l}\text { reading comprehension } \\
\text { under three conditions } \\
\text { (paper, electronic, no } \\
\text { dictionary), vocabulary } \\
\text { and text comprehension } \\
\text { as well as retention } \\
\text { checked immediately } \\
\text { after the reading task; } \\
\text { paper and portable } \\
\text { electronic dictionaries } \\
\text { used - unknown }\end{array}$ & $\begin{array}{l}167 \text { and } 152 \\
\text { Japanese EFL } \\
\text { students, divided } \\
\text { into upper and } \\
\text { lower proficiency } \\
\text { levels }\end{array}$ & unknown & unknown \\
\hline $\begin{array}{l}\text { Kobayashi } \\
(2007,2008)\end{array}$ & $\begin{array}{l}\text { stage 1. a questionnaire } \\
\text { investigating dictionary } \\
\text { using habits; stage } 2 \text {. } \\
\text { reading comprehension } \\
\text { with paper and pocket } \\
\text { electronic dictionary } \\
\text { routinely used by the } \\
\text { subjects, six open-ended } \\
\text { comprehension } \\
\text { questions; two } \\
\text { vocabulary tests to check } \\
\text { retention, oral } \\
\text { interviews; stage } 3 \text {. a } \\
\text { modified questionnaire }\end{array}$ & $\begin{array}{l}\text { stage 1: } 279 \\
\text { Japanese students } \\
\text { at three } \\
\text { universities, } 22 \\
\text { of them } \\
\text { interviewed at } \\
\text { stage } 2 ; \text { stage } 3 \text { : } \\
97 \text { English } \\
\text { majors }\end{array}$ & $\begin{array}{l}\text { think aloud } \\
\text { retrospective } \\
\text { protocols, } \\
\text { information } \\
\text { audio taped }\end{array}$ & $\begin{array}{l}\text { questionnaire, } \\
\text { students } \\
\text { classified as } \\
\text { typically } \\
\text { paper or } \\
\text { electronic } \\
\text { dictionary } \\
\text { users } \\
\text { according to } \\
\text { their } \\
\text { responses }\end{array}$ \\
\hline
\end{tabular}


Dziemianko, Anna. 'On the use(fulness) of paper and electronic dictionaries.' In Granger, Sylviane and Magali Paquot (eds.), Electronic Lexicography. Oxford: Oxford University Press. Pre-publication draft. Not for quotation or copying.

\begin{tabular}{|c|c|c|c|c|}
\hline Authors & Task & Subjects & $\begin{array}{l}\text { Methods of } \\
\text { monitoring } \\
\text { dictionary } \\
\text { use }\end{array}$ & $\begin{array}{l}\text { Testing } \\
\text { familiarity } \\
\text { with PD and } \\
\text { ED }\end{array}$ \\
\hline $\begin{array}{l}\text { Koyama and } \\
\text { Takeuchi } \\
(\mathbf{2 0 0 7 )}\end{array}$ & $\begin{array}{l}\text { study 1: reading two } \\
\text { texts with access to } \\
\text { different dictionaries and } \\
\text { circling the words } \\
\text { looked up; Taishukan's } \\
\text { Genius English- } \\
\text { Japanese Dictionary ( } 3^{\text {rd }} \\
\text { edition) on paper and its } \\
\text { electronic version on } \\
\text { CASIO EX-word XD- } \\
\text { R9000; a two-question } \\
\text { comprehension quiz } \\
\text { immediately afterwards; } \\
\text { study 2: the same } \\
\text { dictionaries and } \\
\text { procedures, but a more } \\
\text { difficult text; a six- } \\
\text { question comprehension } \\
\text { test after the reading task }\end{array}$ & $\begin{array}{l}\text { study } 1: 34 \\
\text { Japanese college } \\
\text { students (false } \\
\text { beginners); study } \\
2: 31 \\
\text { undergraduate } \\
\text { students (much } \\
\text { more advanced in } \\
\text { English) }\end{array}$ & $\begin{array}{l}\text { observation } \\
\text { (each subject } \\
\text { performed the } \\
\text { tasks } \\
\text { individually) }\end{array}$ & $\begin{array}{l}\text { orientation } \\
\text { session, } \\
\text { interview }\end{array}$ \\
\hline $\begin{array}{l}\text { Lew and } \\
\text { Doroszewska } \\
(2009)\end{array}$ & $\begin{array}{l}\text { a purpose-built server- } \\
\text { based online application } \\
\text { with a vocabulary pre- } \\
\text { test and a reading } \\
\text { comprehension task, } \\
\text { unexpected immediate } \\
\text { paper-based retention } \\
\text { and reading } \\
\text { comprehension tests }\end{array}$ & $\begin{array}{l}\text { 56 Polish high } \\
\text { school students, } \\
\text { A2-B1 (CEFR) }\end{array}$ & $\log$ files & unknown \\
\hline
\end{tabular}


Dziemianko, Anna. 'On the use(fulness) of paper and electronic dictionaries.' In Granger, Sylviane and Magali Paquot (eds.), Electronic Lexicography. Oxford: Oxford University Press. Pre-publication draft. Not for quotation or copying.

\begin{tabular}{|c|c|c|c|c|}
\hline Authors & Task & Subjects & $\begin{array}{l}\text { Methods of } \\
\text { monitoring } \\
\text { dictionary } \\
\text { use }\end{array}$ & $\begin{array}{l}\text { Testing } \\
\text { familiarity } \\
\text { with PD and } \\
\text { ED }\end{array}$ \\
\hline Chen (2010) & $\begin{array}{l}\text { a vocabulary test with } \\
\text { both receptive and } \\
\text { productive tasks; the } \\
\text { comprehension part - } \\
\text { choice between three } \\
\text { possible meaning } \\
\text { explanations (exact, } \\
\text { approximate and } \\
\text { irrelevant) of ten low- } \\
\text { frequency words; the } \\
\text { productive part - } \\
\text { sentence formation with } \\
\text { each target word; Oxford } \\
\text { Advanced Learner's } \\
\text { English-Chinese } \\
\text { Dictionary (6 } 6^{\text {th }} \text { edition), } \\
\text { a bilingualised version of } \\
\text { OALDCE6 and other } \\
\text { bilingualised learner's } \\
\text { dictionaries included in } \\
\text { the portable dictionaries } \\
\text { owned by the subjects; } \\
\text { immediate retention test; } \\
\text { one week later an } \\
\text { unexpected retention test } \\
\text { followed by a } \\
\text { questionnaire }\end{array}$ & $\begin{array}{l}85 \text { advanced } \\
\text { students, junior } \\
\text { English majors at } \\
\text { Putian } \\
\text { University, } \\
\text { Fujian }\end{array}$ & $\begin{array}{l}\text { observation } \\
\text { by the author }\end{array}$ & questionnaire \\
\hline $\begin{array}{l}\text { Dziemianko } \\
\text { (2010) }\end{array}$ & $\begin{array}{l}\text { explaining the meaning } \\
\text { of nouns and phrases in } \\
\text { the decoding task, } \\
\text { completing the missing } \\
\text { prepositions removed } \\
\text { from collocations placed } \\
\text { in sentences in the } \\
\text { encoding task; } \\
\text { COBUILD6 on paper } \\
\text { and on the internet; an } \\
\text { unexpected retention test } \\
\text { two weeks later }\end{array}$ & $\begin{array}{l}64 \text { students at } \\
\text { English at Adam } \\
\text { Mickiewicz } \\
\text { University in } \\
\text { Poznań, Poland, } \\
\text { B2-C1 (CEFR) }\end{array}$ & $\begin{array}{l}\text { observation } \\
\text { by the author }\end{array}$ & questionnaire \\
\hline Lew (2010) & $\begin{array}{l}\text { completing partial } \\
\text { English translations, } \\
\text { OALDCE7 entries } \\
\text { (modified - menus, } \\
\text { unmodified - shortcuts) } \\
\text { on paper }\end{array}$ & $\begin{array}{l}90 \text { Polish high } \\
\text { school students } \\
\text { A2-B1 (CEFR) }\end{array}$ & $\begin{array}{l}\text { record sheets, } \\
\text { peer } \\
\text { observation }\end{array}$ & unknown \\
\hline
\end{tabular}


Dziemianko, Anna. 'On the use(fulness) of paper and electronic dictionaries.' In Granger, Sylviane and Magali Paquot (eds.), Electronic Lexicography. Oxford: Oxford University Press. Pre-publication draft. Not for quotation or copying.

\begin{tabular}{|c|c|c|c|c|}
\hline Authors & Task & Subjects & $\begin{array}{l}\text { Methods of } \\
\text { monitoring } \\
\text { dictionary } \\
\text { use }\end{array}$ & $\begin{array}{l}\text { Testing } \\
\text { familiarity } \\
\text { with PD and } \\
\text { ED }\end{array}$ \\
\hline $\begin{array}{l}\text { Lew and } \\
\text { Tokarek } \\
(\mathbf{2 0 1 0})\end{array}$ & $\begin{array}{l}\text { guided Polish-to-English } \\
\text { translation under three } \\
\text { conditions: no menu, } \\
\text { menu, menu + } \\
\text { highlighting; a purpose- } \\
\text { built, Polish-English } \\
\text { online mini-dictionary }\end{array}$ & $\begin{array}{l}90 \text { Polish } \\
\text { learners of } \\
\text { English A2-B1 } \\
\text { (CEFR) }\end{array}$ & $\begin{array}{l}\text { observation } \\
\text { (tasks } \\
\text { performed } \\
\text { individually), } \\
\text { log files }\end{array}$ & unknown \\
\hline $\begin{array}{l}\text { Nesi and } \\
\text { Tan }(2011)\end{array}$ & $\begin{array}{l}\text { relevant sense } \\
\text { identification in paper- } \\
\text { based purpose-built } \\
\text { entries }\end{array}$ & $\begin{array}{l}124 \text { students at a } \\
\text { university in } \\
\text { Malaysia (Bands } \\
\text { 2-6 in terms of } \\
\text { Malaysian } \\
\text { University } \\
\text { Entrance Test } \\
\text { scores) }\end{array}$ & $\begin{array}{l}\text { a clock } \\
\text { embedded in } \\
\text { a purpose- } \\
\text { built Moodle- } \\
\text { based test to } \\
\text { record time }\end{array}$ & $\begin{array}{l}\text { briefing } \\
\text { session }\end{array}$ \\
\hline Tono (2011) & $\begin{array}{l}\text { sense localisation in } \\
\text { purpose-built dictionary } \\
\text { entries shown on the } \\
\text { screen }\end{array}$ & $\begin{array}{l}8 \text { subjects at } \\
\text { Tokyo University } \\
\text { of Foreign } \\
\text { Studies; high } \\
\text { (C1-B2) and low } \\
\text { (A2) proficiency } \\
\text { groups (CEFR) }\end{array}$ & eye-tracking & $\begin{array}{l}\text { briefing } \\
\text { session }\end{array}$ \\
\hline
\end{tabular}


Dziemianko, Anna. 'On the use(fulness) of paper and electronic dictionaries.' In Granger, Sylviane and Magali Paquot (eds.), Electronic Lexicography. Oxford: Oxford University Press. Pre-publication draft. Not for quotation or copying.

\section{Dictionaries}

[CALD3] Walter, Elizabeth. (ed.) (2008) Cambridge Advanced Learners' Dictionary. (3rd edition). Cambridge: Cambridge University Press. (http://dictionary.cambridge.org/dictionary/ learner-english/)

Cambridge Dictionaries Online (http://dictionary.cambridge.org/)

[COBUILD6] Sinclair, John M. (ed.) (2008) Collins COBUILD Advanced English Dictionary. (6th edition). Boston: Heinle Cengage Learning, Glasgow: Harper Collins Publishers. (http://mycobuild.com/)

Dictionary.com (http://dictionary.reference.com/)

TheFreeDictionary (http://www.thefreedictionary.com/)

[LDOCE5] Mayor, Michael (ed.) (2009) Longman Dictionary of Contemporary English. (5th edition). Harlow: Longman. (http://www.ldoceonline.com/)

[OALDCE5] Crowther, Jonathan (ed.) (1995) Oxford Advanced Learner's Dictionary of Current English. (5th edition). Oxford: Oxford University Press.

[OALDCE6] Wehmeier, Sally (ed.) (2000) Oxford Advanced Learner's Dictionary of Current English. (6th edition). Oxford: Oxford University Press.

[OALDCE7] Wehmeier, Sally (ed.) (2005) Oxford Advanced Learner's Dictionary of Current English. (7th edition). Oxford: Oxford University Press.

[MEDAL2] Rundell, Michael (ed.) (2007) Macmillan English Dictionary for Advanced Learners. (2nd edition). Oxford: Macmillan Education.

[MEDO] Macmillan English Dictionary Online. (http://www.macmillandictionary.com/)

Wiktionary (http://en.wiktionary.org/)

WordReference.com (http://wordreference.com/)

\section{References}

Almind, R. (2005) Designing internet dictionaries. Hermes 34: 37-54.

Aust, Ronald, Mary Jane Kelley and Warren B. Roby (1993) The use of hyper-reference and conventional dictionaries. Educational Technology Research and Development 41: 6373.

Béjoint, Henri (2010) The Lexicography of English. Oxford: Oxford University Press.

Bergenholtz, Henning and Rufus Gouws (2007) The access process in dictionaries for fixed expressions. Lexicographica. International Annual for Lexicography 23: 237-260.

Carr, Michael (1997) Internet dictionaries and lexicography. International Journal of Lexicography 10(3): 209-230.

Chen, Yuzhen (2010) Dictionary use and EFL learning: A contrastive study of pocket electronic dictionaries and paper dictionaries. International Journal of Lexicography 23(3): 275-306.

Craik, Fergus I. M. and Robert S. Lockhart (1972) Levels of processing: A framework for memory research. Journal of Verbal Learning and Verbal Behavior 11: 671-684.

Craik, Fergus I. M. and Endel Tulving (1975) Depth of processing and the retention of words in episodic memory. Journal of Experimental Psychology: General 104(3): 268-294. 
Dziemianko, Anna. 'On the use(fulness) of paper and electronic dictionaries.' In Granger, Sylviane and Magali Paquot (eds.), Electronic Lexicography. Oxford: Oxford University Press. Pre-publication draft. Not for quotation or copying.

De Schryver, Gilles-Maurice (2003) Lexicographers' dreams in the electronic-dictionary age. International Journal of Lexicography 16(2): 143-199.

De Schryver, Gilles-Maurice and David Joffe (2004) On how electronic dictionaries are really used. In Geoffrey Williams and Sandra Vessier (eds.), Proceedings of the 11th EURALEX. International Congress EURALEX 2004, Lorient, France, July 6th-10th 2004, 187-196. Lorient: EURALEX.

Dziemianko, Anna (2010) Paper or electronic? The role of dictionary form in language reception, production and the retention of meaning and collocations. International Journal of Lexicography 23(3): 257-273.

Fuertes-Olivera, Pedro A. (2009) The function theory of lexicography and electronic dictionaries: Wiktionary as a prototype of collective free multiple-language internet dictionary. In Henning Bergenholtz, Sandro Nielsen and Sven Tarp (eds.), Lexicography at a Crossroads: Dictionaries and Encyclopedias Today, Lexicographical Tools Tomorrow, 99-134. Bern: Peter Lang.

Guillot, M-N. and M-M. Kenning (1994) Electronic monolingual dictionaries as language learning aids: A case study. Computers in Education 23: 63-73.

Harley, Andrew (2000) Cambridge dictionaries online. In U. Heid, S. Evert, E. Lehmann and C. Rohrer (eds.), Proceedings of the Ninth Euralex International Congress, EURALEX 2000, Stuttgart, Germany, August 8th-12th, 2000, 85-88. Stuttgart: Institut für Maschinelle Sprachverarbeitung, Universität Stuttgart.

Hartmann, Reinhard R. K. and Gregory James (1998) Dictionary of Lexicography. London and New York: Routledge.

Hulstijn, Jan H. and Batia Laufer (2001) Some empirical evidence for the involvement load hypothesis in vocabulary acquisition. Language Learning 51: 539-558.

Kobayashi, Chiho (2007) Comparing electronic and printed dictionaries: Their effects on lexical processing strategy use, word retention and reading comprehension. In K. Bradford-Watts (ed.), JALT 2006 Conference Proceedings, 657-671. Tokyo: JALT.

Kobayashi, Chiho (2008) The use of pocket electronic and printed dictionaries: A mixedmethod study. In K. Bradford Watts, T. Muller and M. Swanson (eds.), JALT 2007 Conference Proceedings, 769-783. Tokyo: JALT.

Koyama, Toshiko and Osamu Takeuchi (2003) Printed dictionaries vs. electronic dictionaries: A pilot study on how Japanese EFL learners differ in using dictionaries. Language Education and Technology 40: 61-79.

Koyama, Toshiko and Osamu Takeuchi (2004) Comparing electronic and printed dictionaries: How the difference affected EFL learning. JACET Bulletin 38: 33-46.

Koyama, Toshiko and Osamu Takeuchi (2007) Does look-up frequency help reading comprehension of EFL learners? Two empirical studies of electronic dictionaries. CALICO Journal 25(1): 110-125.

Laufer, Batia and Zahava Goldstein (2004) Testing vocabulary knowledge: Size, strength and computer adaptiveness. Language Learning 54: 399-436.

Laufer, Batia and Monica Hill (2000) What lexical information do L2 learners select in a CALL dictionary and how does it affect word retention? Language Learning and Technology 3: 58-76.

Laufer, Batia and Jan H. Hulstijn (2001) Incidental vocabulary acquisition in a second language: The construct of task-induced involvement. Applied Linguistics 22: 1-26.

Lehr, Andrea (1996). Zur neuen Lexicographica-Rubrik "Electronic dictionaries". Lexicographica. International Annual for Lexicography 12: 310-317. 
Dziemianko, Anna. 'On the use(fulness) of paper and electronic dictionaries.' In Granger, Sylviane and Magali Paquot (eds.), Electronic Lexicography. Oxford: Oxford University Press. Pre-publication draft. Not for quotation or copying.

Lew, Robert (2010a) New ways of indicating meaning in electronic dictionaries: Hope or hype? In Yihua Zhang (ed.), Learner's Lexicography and Second Language Teaching, 387-404. Shanghai: Shanghai Foreign Language Education Press.

Lew, Robert (2010b) Users take shortcuts: Navigating dictionary entries. In Anne Dykstra and Tanneke Schoonheim (eds.), Proceedings of the XIV Euralex International Congress, 1121-1132. Ljouwert: Afûk.

Lew, Robert (2011) Online dictionaries of English. In Pedro A. Fuertes-Olivera and Henning Bergenholtz (eds.), E-Lexicography: The Internet, Digital Initiatives and Lexicography, 230-250. London and New York: Continuum.

Lew, Robert (In press) Space restrictions in paper and electronic dictionaries and their implications for the design of production dictionaries. In Piotr Bański and Beata Wójtowicz (eds.), Issues in Modern Lexicography. München: Lincom Europa.

Lew, Robert and Joanna Doroszewska (2009) Electronic dictionary entries with animated pictures: Lookup preferences and word retention. International Journal of Lexicography 22(3): 239-257.

Lew, Robert and Patryk Tokarek (2010) Entry menus in bilingual electronic dictionaries. In: Sylviane Granger and Magali Paquot (eds.), eLexicography in the 21st Century: New Challenges, New Applications, 193-202. Louvain-la-Neuve: Cahiers du CENTAL.

Martin, Willy (1992) On the organization of semantic data in passive bilingual dictionaries. In M. Alvar Ezquerra (ed.), EURALEX '90 Proceedings / Actas del IV Congreso Internacional / IV International Congress, 193-201. Barcelona: Biblograf.

Nesi, Hilary (1999) A user's guide to electronic dictionaries for language learners. International Journal of Lexicography 12(1): 56-66.

Nesi, Hilary (2000a) Electronic dictionaries in second language vocabulary comprehension and acquisition: The state of the art. In U. Heid, S. Evert, E. Lehmann and C. Rohrer (eds.), Proceedings of the Ninth Euralex International Congress, EURALEX 2000, 839-847. Stuttgart: Universität Stuttgart.

Nesi, Hilary (2000b) On screen or in print? Students' use of a learner's dictionary on CDROM and in book form. In P. Howarth and R. Herington (eds.), EAP Learning Technologies, 106-114. Leeds: University Press.

Nesi, Hilary and Kim Hua Tan (2011) The effect of menus and signposting on the speed and accuracy of sense selection. International Journal of Lexicography 24(1): 79-96.

Nielsen, Sandro (1999) Mediostructures in bilingual LSP dictionaries. Lexicographica. International Annual for Lexicography 15: 90-113.

Nielsen, Sandro (2008) The effect of lexicographical information costs on dictionary making and use. Lexikos 18: 170-189.

Osaki, Satsuki and N. Nakayama (2004) Denshijisyo vs. insatujisyo: Yuyosei to jikkousei no chigainituiteno kosatu [Electronic dictionary vs. paper dictionary: A comparison of the two dictionary studies]. Bulletin of Tokyo Denki University, Arts and Sciences 2: 7783.

Osaki, Satsuki, Natsue Ochiai, Tatsuo Iso and Kazumi Aizawa (2003) Electronic dictionary vs. printed dictionary: Accessing the appropriate meaning, reading comprehension and retention. In Minoru Murata, Shigeru Yamada and Yukio Tono (eds.), Proceedings of ASIALEX '03 Tokyo, 205-212. Tokyo: Asialex.

Prinsloo, Danie J. (2005) Electronic dictionaries viewed from South Africa. Hermes 34: 1135.

Shizuka, Tetsuhito (2003) Efficiency of information retrieval from the electronic and the printed versions of a bilingual dictionary. Language Education and Technology 40: 15-33. 
Dziemianko, Anna. 'On the use(fulness) of paper and electronic dictionaries.' In Granger, Sylviane and Magali Paquot (eds.), Electronic Lexicography. Oxford: Oxford University Press. Pre-publication draft. Not for quotation or copying.

Simonsen, Henrik Køhler (2011) User consultation behaviour in internet dictionaries: An eyetracking study. Hermes 46: 75-101.

Stirling, Johanna (2003) The portable electronic dictionary: Faithful friend or faceless foe? (20 April 2011) http://www.elgweb.net/ped-article.html.

Tang, Gloria M. (1997) Pocket electronic dictionaries for second language learning: Help or hindrance? TESL Canada Journal 15(1): 39-57.

Tarp, Sven (2009) Reflections on lexicographical user research. Lexikos 19: 275-296.

Tono, Yukio (2000) On the effects of different types of electronic dictionary interfaces on L2 learners' reference behaviour in productive / receptive tasks. In: U. Heid, S. Evert, E.

Lehmann and C. Rohrer (eds.), Proceedings of the Ninth Euralex International Congress, EURALEX 2000, Stuttgart, Germany, August 8th-12th, 2000, 855-861. Stuttgart: Institut für Maschinelle Sprachverarbeitung, Universität Stuttgart.

Tono, Yukio (2009) Pocket electronic dictionaries in Japan: User perspectives. In Henning Bergenholtz, Sandro Nielsen and Sven Tarp (eds.), Lexicography at a Crossroads: Dictionaries and Encyclopedias Today, Lexicographical Tools Tomorrow, 33-67. Bern: Peter Lang.

Tono, Yukio (2011) Application of eye-tracking in EFL learners' dictionary look-up process research. International Journal of Lexicography 24(1): 124-153.

Tseng, Fan-ping (2009) EFL students' Yahoo! Online bilingual dictionary use behavior. English Language Teaching 2(3): 98-108.

Weschler, Robert and Chris Pitts (2000) An experiment using electronic dictionaries with EFL students. The Internet TESL Journal 6 (29 October 2008) http://www.iteslj.org/ Articles/Weschler-ElectroDict.html.

Wiegand, Herbert Ernst (1996) Textual condensation in printed dictionaries: A theoretical draft. Lexikos 6: 133-158.

$\mathrm{Xu}$, Xiaohui (2010) Study on the effect of dictionary use on second language incidental vocabulary acquisition: An empirical study of college English vocabulary learning strategy. Journal of Language Teaching and Research 1(4): 519-523.

Yamada, Shigeru (2011) The challenges of the shift from print to electronic dictionaries. In Kaoru Akasu and Satoru Uchida (eds.), ASIALEX2011 Proceedings Lexicography: Theoretical and Practical Perspectives, 566-575. Kyoto: Asian Association for Lexicography.

Zaenen, Annie (2002) Musings about the impossible electronic dictionary. In Marie-Hélène Corréard (ed.), Lexicography and Natural Language Processing: A Festschrift in Honour of B.T.S. Atkins, 30-44. Stuttgart: Euralex.

\section{Notes}

${ }^{1}$ In the studies by Kobayashi (2007) and Koyama and Takeuchi (2003), users of pocket electronic dictionaries tended to look up more words than those who relied on paper dictionaries, but the differences did not reach statistical significance.

${ }^{2}$ In the electronic (online) version of COBUILD6 used in the study, the entry for the lookedup word does not appear in a sequence of entries on the computer screen, but pops-up alone.

${ }^{3}$ Laufer and Hill (2000: 72) came to virtually the same conclusion; in their words, "the number of times the word is looked up during a learning session bears almost no relation to its 
Dziemianko, Anna. 'On the use(fulness) of paper and electronic dictionaries.' In Granger, Sylviane and Magali Paquot (eds.), Electronic Lexicography. Oxford: Oxford University Press. Pre-publication draft. Not for quotation or copying.

retention". It should be remembered, however, that the CALL software titled Words in Your Ear was used in the study rather than a regular dictionary in electronic form.

${ }^{4}$ Information on the subjects' level of English is given in Table 1 whenever it is specified in the relevant publications.

5. As pointed out above, the interface itself might have been a factor shaping the obtained results as well.

6. Compare the discussion in section 2 . 